\title{
Determination of the Desirable Size of Range Units through the Use of Aggregate Index of Productivity of Factors of Production, A Case Study in the Province of Mazandaran
}

\author{
Abed Vahedi \\ PhD student of Range Management, Department of Range Management \\ Faculty of Agriculture, Islamic Azad University, Science and Research Branch, Tehran, Iran \\ Sadegh Khalilian \\ Department of Agricultural Economy, Faculty of Agriculture \\ Tarbiat Modares University, Tehran, Iran \\ Esmaeil Yasari \\ Assistant Prof. Department of Agriculture, Payame Noor University, 19395-4697 \\ Tehran, Iran \\ E-mail: e_yassari@yahoo.com
}

Received: November 16, 2010 Accepted: November 30, 2010 doi:10.5539/ijb.v3n3p172

\begin{abstract}
Improper utilization of ranges and their destruction have always constituted a major concern of policymakers and planners of the natural resource sector in Iran. In this article, an attempt has been made to use the aggregate index of productivity of factors of production and to present a suitable econometric model for determining the economically correct size of range management projects in the ranges of the province of Mazandaran and to specify factors influencing this size. In this study, the economically suitable size of pasture units was estimated to be 165 hectares, which is much smaller than the size of rangeland turned over to those engaged in range management in the province of Mazandaran. Moreover, results obtained showed that the number of livestock kept in ranges exceeds the economically desirable number. In other words, the suitable balance is not maintained between the size of the range and the number of Livestock kept on it. For this very reason an increase in the size of the range unit managed by each range manager and a reduction in the number of livestock kept on it constitute effective measures in increasing the productivity of ranges and in preventing farther destruction of rangeland, and it is recommended that. These measures are carried out meticulously.
\end{abstract}

Keywords: Rangeland, Productivity, Size, Management

\section{Introduction}

Improper utilization of the ranges in the country and their destruction is one of the problems which has always worried the planners and policymakers of the country, especially the officials in charge of agricultural affairs. On the basis of economic theories, destruction of most natural resources, including pastures, is related to the lack of defined ownership of these resources, because under such circumstances each exploiter tries to get ahead of others in exploiting such resources and through their intensive utilization, to make the most profit out of the available natural resources without being concerned about damages inflicted on them (Baland and Platteau, 1996).

In Iran, in recent years, the ministry of Construction Jihad, as the organization in charge of the ranges in the country, has tried to impose a defined ownership of rangelands through carrying out range management projects in the ranges of the country, to impose a defined ownership of rangelands through carrying out range management projects in the ranges of the country, and in this way to prevent the destruction of ranges and to prepare opportunities for exploiters to invest in ranges and renovate them. 
The definition and determination of ownership rights, of ranges is a necessary, but not sufficient, condition for appropriate exploitation of the ranges in the country and will lead to the protection of resources and to investment in them when the size of pastures and the number of people utilizing them are determined in such a way that maximum exploitation of the combination of the factors of production becomes possible, hence range owners may receive a substantial profit. In other words, the goal of prevention of the destruction of resources and their renovation will be achieved when, together with the determination of ownership rights of ranges in the country, the size of ranges turned over to those engaged in range management is determined in such a way as to make it possible to attain maximum exploitation of the factors of production, hence to maximize profitability of ranges.

In this research, an attempt has been made to use the calculated aggregate index of productivity of the factors of production in range management projects carried out by the organization of Forestry and Ranges of the country in the province of Mazandaran since 1999. It was done to study and determine the economically suitable size of range units in the area under study and the factors affecting this size. Results of this study may provide planners and policymakers of range management projects with useful information to become aware of the effects of policies of the past and to use the information as a guide in turning over ranges to exploiters in the future.

\section{Methodology}

From the economy of production point of view, a pasture unit is a productive establishment which essentially operates with the purpose of maximizing livestock product, such as milk, yoghurt, butter, and of increasing the number of livestock. In this range unit, the total livestock products and the stock produced (TPPi) is a function of the total number of stock kept in the range (Si), the quantity of range forage produced (Xsi), The amount of forage bought from outside the range (Xbi), and the work force employed at the unit to raise stock and to produce forage. Therefore, it can be defined as following:

$$
\mathrm{TPPi}=\mathrm{f}\left(\mathrm{S}_{\mathrm{i}}, \mathrm{Xs}_{\mathrm{i}}, \mathrm{Xb}_{\mathrm{i}}, \mathrm{L}_{\mathrm{i}}\right)
$$

The quantity of forage produced is itself a function of the rainfall $\left(\mathrm{R}_{\mathrm{i}}\right)$, the topographic features of the rangeland, and the soil type. The investment made for the preparation of the land, fertilization, seeding, provision of the water supply, and the intensity of grazing are a function of the number of stock kept per unit area of rangeland (Sri), that is we have the following equation:

$$
\mathrm{Xs}_{\mathrm{i}}=\mathrm{f}\left(\mathrm{R}_{\mathrm{i}}, \mathrm{K}_{\mathrm{i}}, \mathrm{Sr}_{\mathrm{i}}, \mathrm{T}\right)
$$

By substituting equation 2 in equation 1, we get equation 3 in which the total production (TPP) is a Function of the above mentioned Factors and is expressed as follows:

$$
\mathrm{TPPi}=\mathrm{f}\left(\mathrm{S}_{\mathrm{i}}, \mathrm{X}_{\mathrm{i}}, \mathrm{Xb}_{\mathrm{i}}, \mathrm{L}_{\mathrm{i}}, \mathrm{R}, \mathrm{K}_{\mathrm{i}}, \mathrm{SR}_{\mathrm{i}}, \mathrm{T}\right)
$$

Since the total productivity of the factors of production is defined as the output obtained from a specified quantity of the total production inputs (Diewert, 1992), if the set of the factors of production in the $\mathrm{L}_{\mathrm{i}}$ range unit in equation 3 is denoted by $\mathrm{M}_{\mathrm{I}}$, them the aggregate productivity of the factors of production in the range unit can be calculated from equation 4 :

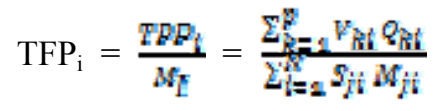

Where $\mathrm{M}_{\mathrm{ji}}$ shows the $\mathrm{L}_{\mathrm{i}}$ quantity of inputs used in the $\mathrm{L}_{\mathrm{i}}$ range unit and $\mathrm{Sji}$ denotes the share of the $\mathrm{L}_{\mathrm{i}}$ input from the total production costs at the $\mathrm{L}_{\mathrm{i}}$ range unit. In other words, $\mathrm{M}_{\mathrm{I}}$ is a weighted sum of all the inputs used at the $\mathrm{L}_{\mathrm{i}}$ range unit. On the other hand is the, $Q_{k t}$ is the $\mathrm{k}^{\text {th }}$ quantity of products produced at the $\mathrm{L}_{\mathrm{i}}$ range unit, and $\mathrm{V}_{\mathrm{ki}}$ is the share of the $\mathrm{k}^{\text {th }}$ product from the total sale of products at this range unit.

The aggregate productivity of the factors of production in a production unit shows how the available resources are used at the unit, when the aggregate productivity of the factors of production at production unit $i$ is compared with the aggregate productivity at unit $\mathrm{j}$, the triple effects of differences in production technology, differences in scale of production, and differences in efficiency of using factors of production e., the movement from within towards the production frontier function between the two production units will be shown. In other words, the productivity gap among production units at a point in time reflects the differences in the technical capability and in the performance of production units which stem from the triple differences mentioned above. If we use TPP to denote productivity at the reference unit, the relative productivity of the range unit I with respect to the reference unit can be expressed as follows (Diewert, 1992): 


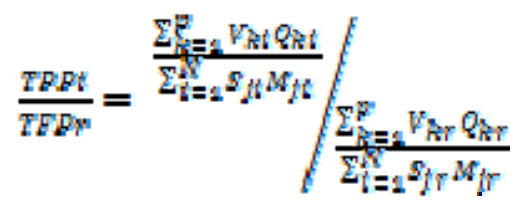

or

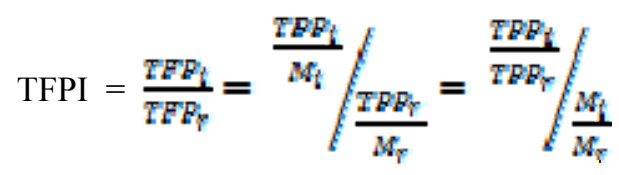

As can be seen in equation 6 , the productivity index of a range unit at a point in time (TTP) is obtained through dividing an aggregate index of the output produced by an aggregate index of the inputs used in the production process.

Since the productivity of most of the factors of production at a production unit, compared to a similar production unit, implies lower average production costs in the first unit as compared with those at the second one, the criterion of production costs is defined as the inverse of the criterion of productivity (Greene, 1993).

Based on this criterion, the production unit having the highest productivity, and hence the lowest production costs, is defined as the most efficient range management unit; and the size of such a unit is defined as the desirable size for a range unit. On the same basis, if the productivity index of the factors of production at a range unit is calculated and the relationship between this index and the size of the production unit is evaluated, the economically suitable size of the production unit can also be calculated.

As was stated before, the scale of production and the efficiency of using production input are among the factors determining the level of productivity and the differences in productivity among production units. The area under range forage crop and crop plant production, and also the number of stock kept per unit area of range, represent the scale of production at the range unit (Campbell and Stafford, 2000). Diversification of production at range units, besides reducing the risks of production, is effective in allowing more appropriate use of the available capacities of the factors of production, especially of the family labor force and of the land, hence in increasing the efficiency of inputs (Campos, 1993). Moreover, the degree of dependence of the range unit on the market for preparing production inputs can also be an effective factor in determining the price risks and hence in allocating the inputs for production and ultimately in finding out the efficiency of production (Barton, 2002). Uncertain property rights are also one factor in not making optimum use of rangeland and it often causes a reduction in the production capacity of range units as well (Anonymous, 2000). Therefore, the type of ownership of range unit, may also be among the effective factors in optimizing the use of the factors of production and hence in increasing the efficiency of production. Finally the production area is a factor representing the sum of technological differences among range units in the form of differences in the quality of the factors of production (especially the soil, the climate, the water, and the weather) and in the way these factors are utilized and it may cause differences in the productivity of range units located in different areas (O"nal, 1997a).

Taking the above points into consideration, the index of productivity (TFPI) can be expressed as a function of all the above-mentioned factors in this relationship:

$$
\text { TFPI }=\mathrm{F}(\mathrm{A}, \mathrm{L}, \mathrm{V}, \mathrm{D}, \mathrm{R}, \mathrm{M}, \mathrm{K}, \mathrm{PR})
$$

Were $\mathrm{A}$ is the area of range forage crop plant land, LV the number of stock kept on the range, D the index of production diversification, $\mathrm{R}$ the region the range unit is located in, $\mathrm{MK}$ the extent of the dependence of the range unit on the market for obtaining production inputs, and PR the type f ownership of the rangeland. Based on equation 7, that area of the range unit and that number of stock kept on the range unit which maximizes TFP are considered the optimum size and number. Therefore, the other variables in equation 7 are treated as shifter factors of the equation.

To obtain the maximum and the minimum points, of the above equation, we have to define a specific mathematical from for the implied relationship in equation 7 . In this study, the following functional form has been employed: 


$$
\text { LnTFPI }=\mathrm{B}_{1}+\mathrm{B}_{2} \mathrm{~A}^{1}+\mathrm{B}_{4} \mathrm{~A}^{1}+\mathrm{B}_{5}(\mathrm{lv})^{1}+\mathrm{B}_{6} \mathrm{D}+\mathrm{B}_{7} \mathrm{R}+\mathrm{B}_{8} \mathrm{MK}+\mathrm{B}_{9} \mathrm{PR}
$$

The reason for choosing the above mentioned functional form is that it can represent any behavior of the TFPI well - i.e., it can represent the shapes of many curves in a tabular form shown in table 1.

Insert Table 1

From the above-mentioned relationships and from what is explained in table 1, it may be inferred that the desirable size of a range unit can be calculated when the parameters $\mathrm{B}_{2}$ and $\mathrm{B}_{3}$ in equation 8 are both less. Than zero, because in that case the behavior of TFPI will match the shape of on inverted $U$, and hence there will be only one maximum point, and it will be possible to calculate the desirable size of a range unit. Moreover, if TFPI matches the ascendant curve, it implies that the size of the range unit is less than the desirable size, and hence an increase in the size of each manager's range will result in a higher profitability of the range. On the other hand if the behavior of TFPI matches the descendant curve $\left(B_{2}=Q_{1}, B_{3}>0\right)$, the opposite interpretation can be inferred i.e. a decrease in the size of each manager's range will result a higher profitability of the range (Gibon et al., 1999).

It is also possible to generalize the interpretation of the estimated coefficients of the model with respect to the number of stock kept on the range i. e. based on the sign of the coefficients $\mathrm{B}_{4}$ and $\mathrm{B}_{5}$, and similarly on the basis of the size of the range, it will be possible to calculate the desirable size of the range, to indicate the excess stock kept in the range, or to show the need for extra stock for the purpose of increasing productivity, and hence of increasing profitability. In each of the abovementioned cases, the other factors in equation 8 which influence TFPI, depending on the sign of the corresponding parameter, will show their effect by increasing or decreasing the profitability associated with a given size of the range or a given number of stock - i.e., all of them are considered as shifters of the TFPI curve (Lasseur, 2005).

\section{Statistical Information and Definition of Variables}

Based on equation 5, in order to calculate the criterion of productivity in a range unit, information about revenues and costs, and about the components of each one, must be gathered. Revenues include the value of the range forage and the crop plants produced on the range, such as range forage, wheat, barley, alfalfa, the value of the by-products of such crops, the value of various stubble produced, and also the value of the main animal products produced, which include meat, milk, and by products such as manure (Aylward, 2002). Therefore, we must know the quantity and the unit price of each of the main and by products mentioned above. The costs also include the value of all the production inputs used at different stages of producing the above- mentioned products (Campbell and Stafford, 2000).

In this study, costs relate to four groups of factors of production, which include the land area, the work force, the capital and the intermediate goods. Therefore, the quantity of each of these inputs and its price must be known separately. Moreover, in order to determine the factors influencing productivity through the use of equation 8 , variables such as the index of diversification of production, the extent of the dependence of the range unit on the market in obtaining production inputs, the Type of owner ship of the pasture, and the type of the region where the range is located must be defined and constructed (Corson et al., 2006).

Information needed for this study was gathered from 36 range unit, out of a total of 85 range unit in the province of Mazandaran using the simple random sampling method.

In this study, each of the previously mentioned variables was defined based on economic concepts and constructed using initial raw information Land area, work force, capital, and intermediate goods are the four main groups of inputs used in range management projects. Land area is defined as the range unit, in hectares, turned over to the pasture manager. In range units, the land often is given to the range manager free of charge. Only in cases where the government has made some preliminary investment, on rangeland is the range manager charged a free as the yearly grazing right. In such cases, the money charged by the government for each hectare of rangeland is considered as the price of this input.

The work force includes the number of days each member of the range manager's family works on the range plus the laborers employed by the manager of the range. These laborers work at various stages of range forage and crop plant production and also in raising stock and in tending them. Wages paid to the employed workers is considered as the wage rate of the work force (the employed workers and the members of the manager's family who work on the range). Therefore, labor cost is calculated through multiplying the total number of days worked on the range by this wage rate.

To calculate the capital input, we must first distinguish stock of capital from capital input. Basically, capital goods are durable goods which are not completely consumed in one production cycle - i.e., a part of them is consumed at each cycle of them is consumed at each cycle of production. Therefore, economists distinguish 
stock of capital from capital input. The capital input is that part of the stock of capital which is consumed during each cycle of production. Therefore, the theory of capital input is defined as follows (Ward, 1976):

$$
\mathrm{QK}=\mathrm{krk}+\mathrm{RFP}+\mathrm{DEPN}
$$

Where $\mathrm{k}$ is the cost of purchasing capital goods such as valves or taps, and $\mathrm{rk}$ is the average cost of each capital unit (an average bank interest rate). This component is actually the opportunity cost of the capital used for buying capital goods. REP is the yearly maintenance cost. DEPN is the cost of yearly depreciation, and QK is the capital or services input taken from the stock of capital and used during each cycle of production. In cases where part of the capital is rented by the range manager, the rent paid is also considered as another component of the capital input. Therefore, the total capital input for such a case is expressed by the following equation:

$$
\mathrm{QK}=\mathrm{krk}+\mathrm{REP}+\mathrm{DEPN}+\mathrm{RENT}
$$

In range management projects, the range managers make numerous investments. First, the manager of the range invests some money to restore and improve his rangeland (Cros et al., 2004).

These investments include hand preparation, fertilization, hill drop, counter furrow, and similar operation. Since such investments increase the value of the rangeland and they do not depreciate, the only opportunity cost of this part of investments as capital input concerns the purchase of barbed wire and the construction of watering troughs to store water for the stock. The opportunity cost plus the yearly depreciation of such investments are considered as the capital input of this component of investments (Johnson et al., 2001).

The other part of investments, which is the main part, concerns the purchase of stock for fattening and for producing animal products. In this case, the opportunity cost of capital plus the cost of the death of stock (depreciation of capital) are regarded as the capital input of this component of the total capital input. The opportunity cost of this component of the capital is the commission paid for the capital used in buying stock at the beginning of the cycle of production. The total capital input in this study consists of the three components mentioned above (Lasseur, 2005).

In this study, bank interest rates were used to calculate opportunity costs since the effect of interest rates on the productivity of range units has itself been one of the aims of this research, we have calculated opportunity costs using interest rates varying from three to twenty percent. The tree percent interest rate was used to calculate opportunity costs because the commission for loans was three percent according to note three of the budget law i. e., it was supposed that the government would give low interest loans to protect ranges in the country and to encourage range managers to invest in ranges.

Intermediate goods are another factor of production and they include materials such as fertilizers, pesticides seeds, water, forage, and medicines for stock. The total value of these materials is used as the intermediate goods input.

The index of production diversification is defined as the inverse of the Herfindahl index and is expressed using the following equation (Robidoux and lester, 1994).

$$
\mathrm{D}=\frac{1}{\sum_{i=2}^{m a t}}
$$

Where ai is the share of each product of the total revenues of the range unit. This index indicates the effects of diversification in production on the productivity of the range unit. Since diversification in production allows the utilization of all available capacities on the range, it is expected that it will have a positive effect on the productivity, and hence on the profitability, of the range unit (Pender and Scherr, 1999).

The variable of dependence on the market for preparing production inputs is defined as the ratio of the cost of forage produced to the total forage used on the productive range unit (Zilberman and Marra, 1993). Since the bigger this ratio is the less the risk of not obtaining production inputs in time and of not optimally using these inputs will be, it is expected this ratio will have a positive effect on the productivity of the range unit.

The variable of the type of ownership of ranges is defined as a virtual variable - i.e., private ownership of ranges was set against group and cooperative ownership of ranges and was compared with them.

\section{Conclusions}

On the basis of equation 6 , the index of productivity of range units was calculated. This index was used as the dependent variable in equation 8 . The parameters of the above mentioned equation were estimated by using the econometric computer software. Chasem; and the results are reported in table 2. 


\section{Insert Table 2}

According to the table 1 when the coefficients of the variable of the size of range $(A)^{1}$ are both negative, the variable is in the shape an inverted $\mathrm{U}$ in relation to the variable TFPI.

This implies that the function of productivity has one maximum point. Therefore by differentiating the productivity function with respect to the variable of the size of range, we can determine the desirable size of the pasture unit, that is:

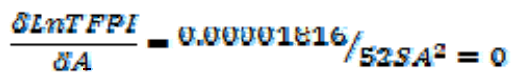

By solving equation 12, the desirable size of a range unit for each family is found to be 165 hectares. Considering the fact that the average area of rangeland managed at each range unit is 98 hectares, it can be said that the area of range units turned over to range managers present is less than the economically desirable area. In other words, if a larger piece of rangeland is turned over to each range manager, the productivity of the range unit, and its profitability, will increase (Solano et al., 2000).

The variables of " the number of members of each range management project ", " ownership of rangeland ", " the dependence of the range unit on the market for obtaining production inputs ", and " production diversification $"$ are considered among the shifter parameters of the productivity equation 8 . For example, from the sign of the variable parameter of rangeland ownership, it is inferred that increasing the size of rangeland managed by each range manager will not have the same effect on range units which are managed differently. This effect concerns range units managed by more than one person (Thompson, 1997). In other words, turning over rangeland to private individuals, rather than to cooperatives and other forms of group management where more than one person manages the range unit, will cause an increase in the productivity of range unit in the area under study.

The positive sign of the variable of the index of dependence on the market also shows the fact that the more of the forage needed for feeding stock is produced by the range manager, the higher the productivity of the range unit will be. The variable of dependence on the market is defined as the quantity of forge produced on the range unit in relation to the total amount of forage needed to feed the stock on the range. In other words, this variable is a ratio the numerator of which is the quantity of forage produced on the range and the denominator is the total amount of forage needed by the stock kept on the range. Therefore, for this ratio to be large, which will imply less dependence on the market, the numerator of the fraction must be big or the denominator is small. A big numerator for this fraction signifies the suitability of the land to be used as rangeland because, firstly, a big harvest of range forage has been possible and, secondly, the type of land has been suitable for growing forage Crops such as barley and alfalfa. On the other hand, a big denominator indicates an excessive number of stock are kept on the range unit. Therefore, the positive sign of the variable of dependence on the market signifies the fact that the better the quality of the rangeland turned over to range managers and hence the more suitable the rangeland is for producing range forage and also the fewer the relative number of stock kept on the farm, the higher the productivity of the range unit will be. This goal can be achieved by increasing the area of rangeland turned over to each range manager, or by making more investments to improve the quality of rangeland so as to increase their yield, and also by reducing the number of stock kept on the range (Thompson, 1997).

The variable of the index of production diversification is another variable that acts as a shifter of the profitability curve in equation 8 this variable also has a positive sign, although it is not significant at the level of as 95 percent probability. The positive sign of the above - mentioned variable in the model shows the fact that the effect of increasing the size of range unit on productivity is 31 percent higher in ranges where the production diversification is higher as compared to ranges where diversification of production is lower; which implies that the point of maximum profitability will be shifted upward by the same extent.

Producing more than one kind of product will, firstly, reduce the risks to the revenues, because if there is a problem in the production of one product (for example its price goes down or its yield is decreased). The revenues of the producer will not suddenly decrease. Moreover, production diversification will lead to utilization of all the available capacities all year round, because keeping stoke a long wilt producing crop plants and keeping milk cows together with meat animals is basically for the purpose of making optimum use of the family work force all year - round. So, the results obtained are as expected (Corson et al., 2006).

Based on table 2, the number of stock on the range also forms a curve in the shape an inverted $U$ in relation to the independent variable of productivity. Therefore, similar to determining the desirable size of the range unit, the desirable number of stock on the range can also be calculated. To do this, we must differentiate equation 8 with respect to the above - mentioned variable and set the result equal to zero: 


$$
\frac{\delta L_{n} T F P L}{\delta L V}=0.0000511916(L V)^{2}=0
$$

By solving equation 13, the desirable number of stock kept in the range management project is found to be 1543 head. With this number of stock (other variables being constant), the productivity of the range unit is maximized. Since the average number of stock kept on a typical range unit is 1962 head, it can be said that the number of stock presently kept on a range unit is more than the desirable number.

Therefore, a decrease in the number of stock on the range units will cause an increase in their productivity. This result, while confirming previous ones, emphasize the need to reduce the number of stock kept on range units. In other words, the result obtained from this component also puts more emphasis on the necessity of creating a balance between the number of stock and the area of the rangeland (O"nal, 1997b).

In conclusion, based on the results obtained in this study, it can be said that increasing the area of rangeland managed by each range manager and decreasing the number of stock on each range unit are effective measures in increasing the productivity and the profitability of range units and in preventing further destruction of ranges. It is recommended that these measures be carefully carried out.

\section{References}

Anonymous. (2000). Manual on the Economics Accounts for Agriculture and Forestry EAA/EAF 97 (Rev. 1.1). Office for Official Publications of the European Communities, Luxembourg, $181 \mathrm{pp}$.

Aylward, B. (2002). Land-use, hydrological function and economic valuation. Paper Read at UNESCO Symposium/Workshop on Forest-Water-People in the Humid Tropics, July 31- August 4, 2002, at Kuala Lumpur, Malaysia.

Baland, J. and Platteau, J. (1996). Halting Degradation of Natural Resources: Is There a Role for Rural Communities? (Oxford, UK).

Barton, D.N. (2002). The transferability of benefit transfer: contingent valuation of water quality improvements in Costa Rica. Ecological Economics, 42: 147- 164.

Campos, P. (1993). The total economic value in the agroforestry systems. The Scientific Basis for Sustainable Multiple-Use Forestry in the EC, June. CE, Brussels.

Campbell, B. D. and Stafford Smith, D. M. (2000). A synthesis of recent global change research on pasture and rangeland production: reduced uncertainties and their management implications. Agriculture, Ecosystems \& Environment, 82, 39-55.

Corson, M. S., Skinner, R. H., Rotz, C. A. (2006). Modification of the spur rangeland model to simulate species composition and pasture productivity in humid temperate regions. Agricultural Systems, 87: 169-191.

Cros, M. J., Duru, M., Garcia, F., Martin-Clouaire, R. (2004). Simulating management strategies: the rotational grazing example. Agricultural Systems, 80: 23-42.

Diewert, W. E. (1992). The measurement of productivity, Bulletin of Economic research, pp:1-166.

Gibon, A., Sibbald, A. R., Flamant, J. C., Lhoste, P., Revilla, R., Rubino, R., Sørensen, J. T. (1999). Livestock farming systems research in Europe and its potential contribution for managing towards sustainability in livestock farming. Livest. Prod. Sci., 61, 121-137.

Greene, W.H. (1993). Econometric Analysis. Macmillian Publishing Co, New York.

Johnson, N., Munk, H., Ravnborg, H.M., Westermann, O., Probst, K. (2001. User participation in watershed management and research. Water Policy, 3 (6), 507- 520.

Lasseur, J. (2005). Sheep farming systems and nature management of rangeland in French Mediterranean mountain areas. Livest. Prod. Sci., 96: 87-95.

O" nal, H. (1997b). Trade off between structural diversity and economic objectives in forest management. American Journal of Agricultural Economics, 79, 1001-1012.

O"nal, H. (1997a). A computationally convenient diversity measure: theory and application. Environmental and Resource Economics, 9, 409-427.

Pender, J. and Scherr, S. (1999). Organizational Development and Natural Resource Management: Evidence from Central Honduras IFPRI, Washington, DC (PRTD Discussion paper No. 49). 
Robidoux, B and J, Lester. (1992). Econometric estimates of scale economies in Canadian manufacturing, Applied Economics, 24:113-122.

Solano, C., Bernues, A., Rojas, F., Joaquin, N., Fernandez, W., Herrero, M. (2000). Relationships between management intensity and structural and social variables in dairy and dual purpose systems in Santa Cruz, Bolivia. Agric. Syst., 65, 159-177.

Thompson, P. B. (1997). The varieties of sustainability in livestock farming. In: Proceedings of the Fourth International Symposium on Livestock Farming Systems, EAAP Publication, vol. 89. Wageningen Press, Wageningen, Denmark, pp. 5-15.

Ward, M. (1976). The measurement of capital, the methodology of capital stock estimation in OECD Countries Organization for Economic Cooperation and Development, Paris.

Zilberman, D. and Marra, M. (1993). Agricultural externalities. In Agricultural and Environmental Resource Economics (G. A. Carlson, D. Zilberman and J. A. Miranowski, eds). New York, NY: Oxford University Press.

Table 1. The shapes of TFPI Curves Based on Estimated Coefficients (Robidoux and Lester, 1992)

\begin{tabular}{|l|l|l|}
\hline $\begin{array}{l}\text { Item } \\
\text { number }\end{array}$ & Notation for the Variable & Shape of the curve \\
\hline 1 & $\mathrm{~B}_{2}, \mathrm{~B}_{3}>\mathrm{Q} \mathrm{B}_{4}, \mathrm{~B}_{5}>\mathrm{O}$ & $\begin{array}{l}\text { TFPI will be U-shaped with respect to the size of the range and the } \\
\text { number of stock in the range, respectively }\end{array}$ \\
\hline 2 & $\mathrm{~B}_{2}, \mathrm{~B}_{3}<\mathrm{Q} \mathrm{B}_{4}, \mathrm{~B}_{5}<\mathrm{O}$ & $\begin{array}{l}\text { TFPI will be in the shape of an inverted U with respect to the size } \\
\text { of the range and the number of stock in the range, respectively }\end{array}$ \\
\hline 3 & $\mathrm{~B}_{2}=\mathrm{QB}_{3}>\mathrm{Q} \mathrm{B}_{4}=\mathrm{QB}_{5}>\mathrm{O}$ & TFPI will be in the shape of curve with negative slope. \\
\hline 4 & $\mathrm{~B}_{2}, \mathrm{QB}_{3}<\mathrm{Q} \mathrm{B}_{4}=\mathrm{QB}_{5}<\mathrm{O}$ & TFPI will be in the shape of curve with positive slope. \\
\hline 5 & $\mathrm{~B}_{2}<\mathrm{QB}_{3}=\mathrm{Q} \mathrm{B}_{4}<\mathrm{QB}_{5}=\mathrm{O}$ & TFPI will be in the shape a line with negative slope. \\
\hline 6 & $\mathrm{~B}_{2}>\mathrm{QB}_{3}=\mathrm{Q} \mathrm{B}_{4}<\mathrm{QB}_{5}=\mathrm{O}$ & TFPI will be in the shape of a line with positive slope. \\
\hline 7 & $\mathrm{~B}_{2}=\mathrm{QB}_{3}=\mathrm{QB}_{4}=\mathrm{QB}_{5}=\mathrm{O}$ & TFPI will be in the shape of a horizontal line. \\
\hline
\end{tabular}

Table 2. Estimated parameters in the model of determining the desirable size of ranges in the province of Mazandaran

\begin{tabular}{|c|c|c|c|}
\hline $\begin{array}{c}\text { Item } \\
\text { Number }\end{array}$ & Name of the variable & $\begin{array}{c}\text { Value of the } \\
\text { variable }\end{array}$ & $\begin{array}{c}\text { t } \\
\text { Statistic }\end{array}$ \\
\hline 1 & The Y-intercept & 247 & 204.2 \\
\hline 2 & The Area of the Range & -0.000018 & -2.190 \\
\hline 3 & The Inverse of the Area of the Range & -16.525 & -2.337 \\
\hline 4 & The Number of stock on the Range & -0.00005 & -5.171 \\
\hline 5 & The Inverse of the Number of stock on the Range & -119.160 & -6.272 \\
\hline 6 & Diversity in Production & 0.030 & 0.152 \\
\hline 7 & The Index of Dependence on the Market for Obtaining Production & 0.433 & 4.117 \\
\hline 8 & Inputs & -0.023 & -1.342 \\
\hline 9 & The Number of Members in Group Projects & 0.057 & 3.031 \\
\hline 10 & The Number of second-and third-of-kin family members in group & 0.031 & 1.768 \\
\hline 11 & & & 1.303 \\
\hline
\end{tabular}

